\title{
GEOSUL
}

\section{O ETHOS PURITANO, O ESPAÇO ABSOLUTO NEWTONIANO E A GEOGRAFIA INGLESA DOS SÉCULOS XVIII E XIX}

Francisco de Assis Gonçalves Junior ${ }^{1}$

\begin{abstract}
Resumo: Este artigo parte da premissa de que a ética puritana, enquanto expressão de valor e de atitudes para o protestantismo ascético geral tornar-se-ia a principal responsável pelo desenvolvimento científico inglês nos séculos XVIII e XIX. Essa construção, elaborada por Robert K. Merton em seu artigo Puritanismo, pietismo e ciência de 1936 teve como pano de fundo a obra A ética protestante e o espírito do capitalismo de Max Weber publicada em 1904. Nesse trabalho Merton buscou ressaltar algumas especificidades da conduta social advinda do ethos puritano, e que estariam claramente associadas à conduta dos cientistas ingleses. Em nossa construção buscou-se estabelecer um paralelo entre as reflexões de Merton e a leitura do "sistema mundo" presente na estruturação da ciência newtoniana. Por fim buscou-se compreender como o espaço newtoniano acabara influenciando a construção da Geografia inglesa.
\end{abstract}

Palavras-chave: Protestantismo; Espaço; Isaac Newton; Cartografia

\section{THE PURITAN ETHOS, THE NEWTONIAN ABSOLUTE SPACE AND THE ENGLISH GEOGRAPHY OF THE 18TH AND 19TH CENTURIES}

\begin{abstract}
This article assumes that the Puritan ethic, as an expression of value and attitudes to the general ascetic Protestantism would become primarily responsible for the English scientific development in the eighteenth and nineteenth centuries. This construction, developed by Robert K. Merton in his article Puritanism, pietism and science had as background the work The Protestant Ethic and the Spirit of Capitalism by Max Weber published in 1904. On that article Merton aimed to highlight some particular characteristics of the social behavior arising from the Puritan ethos which were clearly associated to the conduct of English scientists. In our construction we aimed to draw a parallel between the reflections of Merton and the reading of the "world system" present in the structure of Newtonian science. Finally we have sought to understand how Newtonian space ended up influencing the English Geography.
\end{abstract}

Key-words: Protestantism; Space; Isaac Newton; Cartography

\section{EL ETHOS PURITANO, EL ESPACIO ABSOLUTO NEWTONIANO Y LA GEOGRAFÍA INGLESA DE LOS SIGLOS XVIII Y XIX}

Resumen: Este artículo parte de la premisa de que la ética puritana, como expresión de valor y de actitudes para el protestantismo ascético general, se convertiría en la principal responsable del desarrollo científico inglés en los siglos XVIII y XIX. Esa construcción, elaborada por Robert K. Merton en su artículo Puritanismo, pietismo y ciencia de 1936 tuvo como telón de fondo la obra La ética protestante y el espíritu del capitalismo de Max Weber publicada en 1904. En ese trabajo Merton buscó que resaltar algunas especificidades de la

\footnotetext{
${ }^{1}$ Docente do Departamento de Geografia da Universidade Federal de Mato Grosso - UFMT - Cuiabá fgjufmt@gmail.com
} 
conducta social derivada del ethos puritano, y que estarían claramente asociadas a la conducta de los científicos ingleses. En nuestra construcción se intentó establecer un paralelo entre las reflexiones de Merton y la lectura del "sistema mundo" presente en la estructuración de la ciencia newtoniana. Por fin se buscó comprender cómo el espacio newtoniano acabó influenciando en la construcción de la Geografía inglesa.

Palabras clave: Protestantismo; Espacio; Isaac Newton; Cartografía

\section{INTRODUÇÃO}

Este artigo se estruturou a partir da análise do contexto histórico (com ênfase ao contexto teológico e filosófico) responsável pela organização do conceito de espaço durante o iluminismo, mais precisamente pela organização do conceito de espaço absoluto realizado por Isaac Newton. Esta análise possibilitou posteriormente a análise das formas de apropriação deste pela Geografia.

Torna-se importante destacar que este artigo não trata das bases que consolidaram o conceito de espaço geográfico entendido como o espaço resultante das relações estabelecidas entre seus próprios elementos. Dessa forma não foram consideradas, por exemplo, as raizes históricas/filosóficas advindas de Leibniz e Kant e do Romantismo alemão, fundamentais para a compreensão da estruturação da Geografia científica com Humboldt e Ritter entre a segunda metadade do século XVIII e a primeira metade do século XIX. A análise proposta neste artigo se estrutura sob outro contexto.

Esta empreitada buscou apontar elementos para a reflexão sobre as bases epistemológicas do saber geográfico, principalmente no que se refere a falta de criticidade social do conceito de espaço utilizado pela Geografia via espaço absoluto.

No "atual" contexto das "hiperespecializações ${ }^{2 "}$ cientificas, redutoras das reflexões epistemológicas na Geografia, esta discussão torna-se importante.

Para esta análise foram considerados três caminhos reflexivos complementares; primeiramente considerou-se que o ethos puritano, enquanto expressão de valor e de atitudes para o protestantismo ascético geral tornar-se-ia o principal responsável pelo desenvolvimento científico inglês nos séculos XVIII e XIX, sendo este marcado principalmente pelas especificidades comportamentais que se refletiam na conduta social dos cientistas ingleses do período, nessa perspectiva foram enfatizadas as ideias de trabalho enquanto vocação, de glorificação da obra divina, do uso da ciência enquanto ferramenta para construção do bem estar social e a ideia do raciocínio como refreador das "paixões". Em um segundo momento

\footnotetext{
${ }^{2}$ Edgar Morin define a" hiperespecialização" como a especialização que se fecha em si mesma, que fragmenta a realidade e que impede o pesquisador de conceber o global. Ver: MORIN, Edgar. A cabeça bem feita: repensar a reforma, reformar o pensamento. Rio de Janeiro: Bertrand Brasil, 2014.
} 
buscou-se estabelecer um paralelo entre estes "códigos de conduta" e a estruturação da ciência newtoniana, tendo por enfâse a construção do conceito de espaço absoluto. Por fim buscou-se traçar uma paralelo entre o conceito de espaço absoluto newtoniano e o viés utilitarista da Geografia imperial inglesa dos séculos XVIII e XIX, principalmente no que refere as suas técnicas cartográficas e topográficas.

\section{O ETHOS PURITANO E O TRABALHO}

A reflexão estruturada por Weber na obra A Ética Protestante e o Espírito do Capitalismo (1904) parte do posicionamento central de que o protestantismo originado nos séculos XVI, XVII e XVIII (assim como suas diferentes vertentes transformadas no tempo histórico) relaciona-se diretamente com o conceito de vocação, principalmente no que se refere a vocação para o trabalho profissional, constituindo, portanto a base "motivacional" do sistema econômico capitalista, a base para consolidação de um "espírito capitalista".

Esta empreitada sociológica de Weber em busca das raízes da dinâmica capitalista revela, dentre outros aspectos, uma significativa distinção entre a formação católica, considerada por ele mais humanista e a formação protestante dos séculos XVI e XVII, mais técnica.

[...] há uma visível diferença em Baden, na Baviera, na Hungria, em relação ao tipo de educação superior que os pais católicos, em oposição aos protestantes, oferecem a seus filhos. [...] entre os católicos graduandos, a porcentagem daqueles que se encontram em instituições de estudos técnicos preparatórios, em particular para ocupações industriais e comerciais, mas em geral naquelas que formam uma vida empresarial, fica ainda mais abaixo da média de protestantes. Por outro lado, os católicos preferem o tipo de formação oferecido pelo Gymnasien humanístico (WEBER, 2013, p.35-36).

Weber afirma que a explicação para a formação distinta entre católicos e protestantes advém de "peculiaridades mentais e espirituais adquiridas no ambiente" (WEBER, 2013, p.36). Ambiente este entendido como a comunidade doméstica e a casa paterna, ou seja, a atmosfera religiosa que envolve o sujeito e que direciona sua profissão.

A formação católica humanista possui como base estruturante a devoção extramundana, transcendental, conduzindo seu ethos a uma maior indiferença em relação à materialidade do mundo.

Não ameis o mundo, nem o que há no mundo. Se alguém ama o mundo, o amor do Pai não está nele. Porque tudo o que há no mundo a concupiscência da carne, a concupiscência dos olhos e a soberba da vida, não vem do Pai, 
mas sim do mundo. Ora, o mundo passa, e a sua concupiscência; mas aquele que faz a vontade de Deus, permanece para sempre (BÍBLIA, João 2:15-17).

Isto explicaria o porquê de os católicos (em uma visão generalista) serem tão pouco engajados aos empreendimentos capitalistas nos séculos XVI e XVII.

No entanto, o antigo protestantismo de Lutero não divergia totalmente dessa formação católica ascética, pois era claramente hostil a diversos aspectos da vida materialista. Nesse sentido é preciso ressaltar que a construção de Weber, no que se refere à ética protestante e o "real espírito do capitalismo", não se vincula ao desejo ou a falta dele pelo desfrute da vida mundana e sim por características puramente religiosas, mais especificamente de conduta religiosa, associada a ideia de vocação para o trabalho profissional que é exclusiva do protestantismo. Não que o objetivo da Reforma Protestante fosse promover um espírito capitalista, nem mesmo a reforma ética era foco dos reformadores, o único intuito era da salvação da alma, sendo este o centro de seus trabalhos e de suas vidas.

É nesse sentido que para Lutero a profissão concreta que cada indivíduo perseguia era um comando de Deus, que preenchia as condutas particulares. A vocação profissional era algo que o homem deveria aceitar como uma ordenação divina, a qual deveria adaptar-se, no entanto:

Embora a Reforma seja impensável sem o desenvolvimento religioso pessoal de Lutero e profundamente influenciado espiritualmente por sua personalidade, sem o calvinismo seu trabalho não poderia ter tido sucesso permanente e concreto (WEBER, 2013, p. 102).

O calvinismo radicalizou a noção de vocação profissional, tendo na predestinação o seu mais característico dogma. Para Calvino o interesse era unicamente Deus, não o homem, como cita Weber:

Deus não existe para os homens, mas os homens para a causa de Deus. Toda criação - incluindo, é claro, o fato de que, como era indubitável para Calvino, apenas uma pequena proporção dos homens é escolhida para a graça eterna - somente pode ter algum significado enquanto meio para a glória e a majestade de Deus (WEBER, 2013, p.133).

A conduta protestante se assentaria sobre um poder presente dentro do próprio indivíduo, que trabalhava para a glória de Deus. Diferente de Lutero, não seria apenas a vontade de Deus que definiria o lugar do indivíduo no mundo do trabalho, mas por intermédio de Deus buscar-se-ia ampliar a obra divina através de trabalhos "úteis" (que ampliariam a glória divina), o que conduziria a certeza da salvação. 
Nesta perspectiva a fé deveria ser provada por seus resultados objetivos, eis o motivo da valorização do trabalho profissional, ao qual se inclui o trabalho científico profissional.

A obra de Calvino obteve um grande sucesso na Inglaterra do século XVII, adentrando também outros países como os Países Baixos e as colônias inglesas, dentre elas os Estados Unidos e a África do Sul.

Nesse contexto, os puritanos, considerados como os mais radicais dentre os calvinistas ingleses, rigorosos e conservadores, lutavam para "purificar" a Igreja da Inglaterra (Anglicana) através de uma Reforma completa, ou seja, através do total rompimento com a liturgia professada pela Igreja Católica Romana. Apesar de altamente combativo, o puritanismo acabou sendo rejeitado pelos líderes anglicanos, pois sua crítica ultrapassava as questões teológicas atingindo também questões de cunho político e econômico.

Por outro lado, o perfil combativo dos puritanos acabou influenciando na discussão de questões importantes durante o período de Reforma na Inglaterra. A ética comportamental puritana por exemplo, apregoava como base para glorificação da obra divina, o trabalho, sem a dicotomia clássica da Igreja Romana entre trabalho secular, entendido como qualquer trabalho humano e trabalho sagrado realizado por membros da profissão religiosa (Ryken, 1992).

Nesta perspectiva Ryken (1992) afirma que:

[...] os Puritanos rejeitaram a dicotomia sagrado-secular. Willian Tyndale disse que se olhamos externamente "há uma diferença entre lavar louça e pregar a palavra de Deus; mas no tocante a agradar a Deus; nenhuma em absoluto". Willian Perkins concordou: " A ação de um partos em guardar ovelhas... é um trabalho tão bom diante de Deus como a ação de um juiz ao sentenciar, ou de um magistrado ao regulamentar, ou de um ministro ao pregar". Esta rejeição da dicotomia entre trabalho sagrado e secular teve implicações de longo alcance (RIKEN, 1992, p.40).

Riken continua o raciocínio indicando que:

Primeiro, considera que toda tarefa de valor intrínseco e integra [sic] toda vocação com a vida espiritual de um cristão. Torna todo o trabalho consequencial, tornando-o arena para a glorificação e obediência a Deus e expressão do amor pessoal (através do serviço) a seu próximo (RYKEN, 1992, p.40)

Assim, o ethos puritano acabara por trazer dignidade ao trabalho secular, pois toda tarefa, por mais simples que fosse, contribuiria para o objetivo puritano de servir a Deus, integrando seu trabalho diário com sua devoção religiosa, o trabalho tornar-se-ia santificado (Ryken, 1992) 
Esta influência da doutrina calvinista do trabalho através de um puritanismo combativo ao longo dos séculos XVI, XVII e XVIII acabou sendo amplamente professada entre os fiéis da Igreja Anglicana.

Neste artigo optamos por não nos aprofundarmos nos desdobramentos sociológicos que a ética religiosa puritana conferiu a organização do trabalho (entendido de forma geral), e que inclusive foi exaustivamente explorado por Weber em sua obra de 1904, assim, enfatizaremos a partir desse ponto apenas os desdobramentos da ética puritana no trabalho dos cientistas ingleses dos séculos XVII, XVIII e XIX.

\section{O ETHOS PURITANO E A CIÊNCIA INGLESA}

Certos elementos da ética puritana deixaram marcas indeléveis nas atitudes de alguns dos principais cientistas ingleses, principalmente no que se refere ao entendimento do papel da ciência e seu método, nesse sentido, destacaremos como alguns desses elementos vinculados ao ethos influenciaram o trabalho desses cientistas.

Primeiramente destacaremos a questão da glorificação da obra divina através do estudo científico da natureza.

O irlandês Robert Boyle foi um dos principais cientistas protestantes desse período na Inglaterra, sendo responsável por realizar, nas palavras de Merton (2013, p.17-18) "uma altamente qualificada apologia à ciência". Seu discurso era sustentado pela ideia de que o estudo da natureza serviria a glorificação da obra de Deus. Esta preocupação de Boyle com a ciência se refletiu inclusive no trecho redigido originalmente em 1692 pelo Bispo Gilbert Burnet $^{3}$, de Salensbury, na ocasião do funeral de Boyle. Nele Gilbert apresenta os últimos desejos de Boyle em relação aos seus pares.

Wishing them also a happy success in these laudable attempts to discover the true nature of the Works of God; and praying that they, and all other searchers into physical truths, may cordially refer their attainments to the glory of the great Author of nature, and to the comfort of mankind (BURNET, 1824, p. 262).

\footnotetext{
${ }^{3} \mathrm{O}$ bispo Gilbert Burnet foi responsável por ouvir algumas das confissões de Robert Boyle, o que justifica a transcrição dos últimos desejos de Boyle, na ocasião de sua morte. Sobre as confissões de Boyle, ver: HUNTER, M. Casuistry in Action: Robert Boyle's Confessional Interviews with Gilbert Burnet and Edward Stillingfleet, 1691. Cambridge: Journal of Ecclesiatic History, vol. 44, nº 1, 1993.
} 
Este trecho sobre o desejo de Boyle, citado por Burnet, apresenta um segundo dogma importante para o entendimento da construção intelectual e científica que estava sendo traçado pelos cientistas ingleses; a busca pelo bem-estar social.

A busca, como afirma Merton (2013, p.20), é do "[...] bem da maioria como um objetivo a ter sempre em mente [...]", nesse caminho a ciência deveria conduzir ao domínio da natureza. $\mathrm{O}$ intuito do cientista inglês seria, portanto, o de também melhorar a vida humana em suas condições materiais, dessa forma, tanto a ciência quanto o cientista estariam ultrapassando seus valores puramente mundanos. A ciência teria uma "missão" uma vez que trabalharia à luz da doutrina de salvação puritana.

Outro ponto importante na correlação entre o ethos puritano e a ciência perpassa as considerações a respeito dos problemas do ócio. Merton (2013 p.21) destaca que "o puritano evita o ócio porque ele conduz a pensamentos pecaminosos". "Que espaço pode haver para as coisas baixas e pequenas em uma mente tão útil e exitosamente empregada?" (SPRAT, 1667 apud. MERTON, 2013, p.21). Nesse sentido, entende-se que o ethos puritano condicionava inclusive a dedicação ao trabalho científico (não exclusivamente), pois caso contrário, o cientista poderia ocupar seu intelecto com questões perniciosas, para satisfação da carne. Este aspecto ascético do puritanismo conduziu muitos dos cientistas ingleses à valorização da razão, uma vez que o raciocínio rigoroso sobre o mundo natural evitaria o ócio e os desejos carnais.

Nesse aspecto, a adequação da ciência ao ethos puritano pode ser resumida da seguinte forma:

A Reforma acabou por transferir o ônus da salvação individual da Igreja para o indivíduo, e é esse "senso de responsabilidade, irresistível e esmagador, por sua própria alma" que explica o agudo interesse religioso. Se a ciência não fosse demonstravelmente uma vocação legitima e desejável, ela não teria merecido atenção daqueles que sentem "sempre sobre o olho do Grande Mestre" (MERTON, 2013, p.22).

A partir dessas afirmações verifica-se que o ethos puritano definiu os valores mais básicos para a construção do pensamento e da prática científica na Inglaterra dos séculos XVII, XVIII e XIX, com destaque para seu caráter empirista e racionalista, mas acima de tudo utilitarista.

Para estes cientistas o foco de análise estaria na compreensão racional da obra divina, pois a natureza seria a manifestação direta do poder e da sabedoria divina. Nesse sentido Merton destaca que: 
Talvez o elemento mais diretamente efetivo da ética protestante para a sanção da ciência natural tenha sido aquele que sustentava que o estudo da natureza permite uma apreciação completa de Seus trabalhos, conduzindo assim a admirar o poder, a sabedoria e a bondade de Deus, tal como se manifesta em Sua criação (MERTON, 2013, p.24).

O mecanicismo tornar-se-ia o principal método de explicação da organização da obra divina, ou em outras palavras, o mecanicismo permitiria a análise das conexões que por sua vez revelariam os papéis desempenhados por cada um dos elementos na natureza, assim como revelariam as razões pelas quais estes elementos estariam alocados em seus devidos lugares, conduzindo os cientistas a estudos sobre a organização espacial de tais elementos.

No entanto este delineamento sobre o mecanicismo só iria se estruturar a partir de uma série de críticas aos desdobramentos teológicos e éticos associados ao atomismo antigo de Epicuro e Lucrécio.

$\mathrm{O}$ atomismo preconizado por Epicuro e Lucrécio considerava o mundo como algo derivado de simples efeitos mecânicos de átomos, assim tudo o que ocorreria na natureza, ou seja, a variedade das coisas observáveis, poderiam ser explicada pelo diferentes tamanhos e formas e pelos diferentes arranjos nos quais os átomos poderiam se combinar (Zaterka, 2004), Deus não seria necessário para a compreensão dos fenômenos da realidade.

Para cientistas como Boyle, o estudo da natureza, acima de tudo, deveria demonstrar, como já dito, a beleza da obra do Criador, já para Epicuro e Lucrécio, a perspectiva era outra: sem conhecermos os mecanismos da natureza, continuaremos atormentados, pelo medo dos deuses e nunca atingiremos a paz (Zaterka, 2004).

Ora, não é casual que Boyle tenha evitado enfaticamente utilizar a palavra atomismo nas suas obras e tenha optado por corpuscularismo. A última coisa que nosso cristão virtuoso almejaria é ser confundido com um ateu, ímpio e materialista (ZATERKA, 2004, p.72).

A crítica de Boyle se assenta justamente nessa perspectiva de remoção de Deus do mundo.

Torna-se interessante destacar que o padre francês Marin Mersenne (1588-1648) antes de Boyle, já alertava para esta ameaça da remoção de Deus do mundo.

Para ele, a ameaça das doutrinas naturalistas estava na concepção de que a matéria seria "ativa", o que retiraria de Deus e dos próprios seres humanos a responsabilidade pelas questões humanas. Se não houvesse atividade alguma na matéria, como queria Mersenne, Deus teria que ser invocado para explicar essa atividade (PESSOA JUNIOR, 2006, p.47). 
Boyle neste contexto, com receio de ser acusado de epicurista e atento as críticas de Mersenne, buscou através do princípio da imanência uma nova via para organização da relação entre Deus e a matéria, diferente inclusive da perspectiva de Descartes que considerava Deus como "motor inicial".

Para Boyle as Leis Universais são resultantes da vontade divina, e não resultantes da simples natureza da matéria, inclusive sua manutenção dependeria de uma constante intervenção de Deus, como demonstra Anstey (2003):

He tells us in the "Excellency of the Mechanical Hypothesis" that the phenomena of the world are physically produced because of "the laws motion being upheld by his incessant concourse and general providence" (Works, IV,pp.68-69, S. p. 139). The idea is that, while matter is causally efficacious in that it can transmit its motion in collisions, the nature of that transmission and the resultant motions are determined by the immanent activity of God (ANSTEY, 2003, p.164).

Assim, a "filosofia mecânica" de Boyle ao mesmo tempo em que se alinha ao objetivo de Mersenne, acaba por ampliar o papel Deus na ciência através do princípio da imanência, fato que faz jus a sua ética protestante.

As descobertas científicas derivadas desse conhecimento mecânico da natureza e que ao mesmo tempo possibilitassem a ampliação do bem estar social, ampliariam ainda mais a glória da obra divina, uma vez que, como já citado na passagem do Bispo Burnet, o homem, único ser da criação dotado de razão, teria de zelar pela obra divina, cuidando inclusive de seus semelhantes. A ciência nesse processo teria a missão de trazer "conforto" a humanidade (Burnet, 1824).

Em contraponto, esta constante busca pela utilidade da natureza, acabara por estabelecer a divisão entre homem e mundo natural.

A natureza passaria a ser vista como algo a ser "dominado", em outras palavras, a natureza por si só em seu devir natural "irracional" seria inferior ao homem, ser racional e principal elemento da criação, eis aqui a influência cartesiana do cogito ergo sum, que juntamente com o ethos puritano utilitarista conduziriam a tal segregação.

$\mathrm{Na}$ Inglaterra protestante desse período houve uma intensa busca pela glorificação da obra divina, no entanto, havia uma clara distinção hierárquica entre o racional e o irracional no que se refere a criação.

A tradição religiosa dominante não mantinha nenhum vínculo com aquela "veneração" da natureza encontrada em várias religiões do Oriente e que o cientista Robert Boyle corretamente reconhecia como um "obstáculo 
desencorajador ao império do homem sobre as criaturas inferiores". Desde os tempos anglo-saxões, a Igreja cristã na Inglaterra colocou-se contra o culto das nascentes e dos rios. As divindades pagãs do bosque, da corrente e da montanha foram expulsas, deixando assim desencantado o mundo, e pronto para ser formado, moldado e dominado (THOMAS, 1988, p.28).

As criaturas inferiores (tanto fauna como flora) teriam sido criadas para o usufruto do homem.

No século XVIII, insistia-se amplamente em que a domesticação era benéfica para os animais [...]. Vacas e ovelhas passavam melhor sob os cuidados do homem que deixadas à mercê de predadores ferozes. Abatê-las par alimento podia parecer cruel, dizia Thomas Robinson em 1709, mas, "quando se examina o assunto mais de perto", isso se mostrava "uma gentileza em vez de crueldade"; o seu fim era rápido e se lhes poupava os sofrimentos da idade. Não havia injustiça quanto a matar o gado para fornecer alimento para "um animal mais nobre", pensava o arcebispo King; foi apenas por essa razão que as bestas foram criadas antes de nós (THOMAS, 1988, p.25).

Este domínio também vai justificar o imperialismo inglês sobre as "raças inferiores" na África e na Índia, como veremos mais a frente.

No que se refere ao ethos puritano, o domínio da natureza acabava por ampliar tanto o valor do trabalho realizado pelo camponês, como o valor do trabalho realizado pelo cientista, em busca de descobertas voltadas ao cultivo e criação de animais, dessa forma ambos estariam no caminho da salvação.

Estas questões, vinculadas a ciência utilitarista foram amplamente discutidas na Royal Society of London for the Improvement of Natural Knowledge, como veremos a seguir. Devido a sua importância em diversas escalas de influência, apontaremos em um primeiro momento algumas questões sobre sua criação e sobre seus membros (ênfase a Newton), para assim estruturarmos o encadeamento lógico almejado na proposta deste artigo.

\section{O PAPEL DA ROYAL SOCIETY E O CONCEITO DE ESPAÇO ABSOLUTO DE NEWTON}

Em meados do século XVII, muitos cientistas ingleses estavam se dedicando entusiasticamente aos métodos experimentais de investigação científica. Neste contexto, alguns dos cientistas londrinos, ou "filósofos experimentais" (como se referia Boyle) realizavam encontros semanais ${ }^{4}$ para discutir seus procedimentos metodológicos, suas hipóteses, a conjuntura e os obstáculos enfrentados pela investigação científica. No intuito de

\footnotetext{
${ }^{4}$ Mais precisamente no Gresham College.
} 
formalizar tais reuniões os membros desse grupo elaboraram em 1660 uma petição ao Rei Charles II para assinatura da Carta Régia que oficializaria suas discussões através da constituição da primeira sociedade científica da Inglaterra. Em 15 de julho de 1662 a Royal Society of London for the Improvement of Natural Knowledge foi oficialmente fundada.

Em 1663 a Royal Society contava com 10 dos mais importantes cientistas da época, dentre eles: Willian Brouncker, matemático e o primeiro presidente da Royal Society; Robert Boyle, pioneiro em experimentos físicos e químicos; John Wilkins, que se tornaria Bispo de Chester, era especialista em matemática e mecânica; Isaac Barrow, matemático e físico, tutor de Isaac Newton; Robert Hooke, matemático que realizou experimentos em ótica, mecânica, arquitetura e astronomia; William Neile, matemático; John Pell, matemático; John Walis, matemático; Cristopher Wren, arquiteto e matemático; Christiaan Huygens, matemático (The Royal Society, 2007).

Os cientistas ou filósofos naturais da Royal Society teriam como método comum de análise, a indução e o experimentalismo, inclusive o lema da sociedade, Nullius in Verba (nas palavras de ninguém), deixava claro a determinação de que nenhuma afirmação seria aceita até ser verificada através da experimentação, o que remete inclusive a uma posição crítica em relação a Escolástica, que tinha como princípio acreditar primeiro nos escritos aristotélicos, os experimentos apenas confirmavam o que dizia Aristóteles, não haviam novos questionamentos.

Talvez o principal diferencial conduzido pelo experimentalismo da Royal Society se assente no fato de que o conhecimento advindo da experimentação deveria passar pelo crivo da opinião "pública", pois só assim o conhecimento natural seria realmente validado. No entanto o acesso aos laboratórios ou áreas de experimentação não se dava a qualquer pessoa, como afirma Livingstone (2003):

Of course the new experimental arenas that surface in the period, not only in Boyle's home but at the Royal Society and elsewhere, were far from public in today's sense. To be sure, "gentlemen" were permited acess, according to the social norms of the day. But most importante was that has been called "the experimental public" - those whose presence was essential to the confirmation of empirical findings (LIVINGSTONE, 2003, p.23-24).

Esta necessidade, mesmo que voltada a uma parcela da população, diga-se; homens letrados, bons cristãos e burgueses, além de outros filósofos experimentais, advém do ethos puritano, pois a verificação "pública" de um trabalho científico perante a sociedade definiria 
seu valor enquanto promotora do bem estar social, inclusive conferindo um grande mérito ao pesquisador.

Torna-se importante frisar que muitos dos experimentos demonstrados publicamente não apontavam para uma utilização imediata, mas deveriam apresentar um potencial para realização de novas descobertas.

A bomba de vácuo criada por Robert Boyle, por exemplo, não fora concebida para uma utilização imediata, no sentido de sua utilização direta pela sociedade em larga escala, mas apresentava um potencial para análise de reações químicas e de movimento no vácuo, ampliando portanto o conhecimento sobre a dinâmica do ar e do "vazio"5 e por assim, dizer ampliando o conhecimento sobre a obra divina.

É sob este contexto experimentalista, explorado pelos membros da Royal Society, que analisaremos o papel marcante de Isaac Newton nas ciências naturais.

Isaac Newton consagrou-se como membro da Royal Society em 1672, assumindo a presidência da instituição em 1703, sendo sucessivamente reeleito até a sua morte em 1727.

No que se refere à religiosidade de Newton, torna-se importante destacar que apesar de sido criado dentro da tradição protestante, muitos dos seus pontos de vista sobre teologia eram exclusivos, pois Newton rejeitava tudo que se associava a um possível misticismo, ou que fosse irracional ou supersticioso dentro dos ritos religiosos. Um importante fato que comprova esse seu viés advém de seus estudos sobre a bíblia que acabaram por conduzi-lo a abandonar, por exemplo, a doutrina da Trindade (Jones, 2011).

No entanto, Newton fora fielmente crente a Deus e a seu modo emerso na doutrina protestante.

A crença de Newton em Deus pode ser verificada em sua obra Opticks: or, a treatise of the reflections, refractions, inflections and colours of light de 1704, sobre a qual Newton aponta uma série de questionamentos sobre a causa primária por detrás da realidade e sobre como o homem percebe a realidade.

What is there in places almoft empty of Matter, and whence is it that the Sun and Planets gravitate towards one another, without denfe Matter between them? Whence is it that Nature doth nothing in vain; and whence arifes all that Order and Beauty which we fee in the World? To what ends are Comets, and whence is it that Planets move all one and the fame way in Orbs

\footnotetext{
${ }^{5}$ É importante destacar que a possibilidade de criação humana do vácuo conduziu a uma série de críticas sobre as explicações religiosas sobre o vazio, fato que por consequência afetaria a discussão sobre o poder absoluto da monarquia na Inglaterra do século XVII. Sobre esta discussão consultar: SHAPIN, S; SCHAEFFER, S. Leviathan and the air-pump: Hobbes, Boyle and the experimental life. Princeton: Princeton University Press, 1985.
} 
concentrick, while Comets move all manner ways in Orbs very excentrick; and what hinders the fix'd Stars from falling upon one another? How came the Bodies of Animals to be contrived with fo much Art, and for what ends were their feveral Parts? Was the Eye contrived without Skill in Opticks, and the ear without Knowledge of Sounds? How do the Motions of the Body follow from the Will, and whence is the Inftinct in Animals? Is not the Senfory of Animals that place to which the fenfitive Substance is prefent, and into which the fenfible Species of Things are carried through the Nerves and Brain, that there they may be perceveid by their immediate prefence to that Substance? And thefe things being rightly difpatch'd, does it not appear from Phaenomena that there is a Being incorporeal, living, inteligente, omniprefent, who infinite Space, as it were in his Senfory, fees the things themfelves intimately, and throughly perceives them, and compreehends them wholly by their immediate preference to himfelf: Of which things the Images only carried through the Organs of Senfe into our little Senforiuns, are there feen and beheld by that wich in us perceives and thinks. And thought every true Step made in this Phylosophy brings us not immediately to the Knowledge of the firft Caufe, yet it brings us nearer to it, and on that account is to be highly valued (NEWTON, 1730, p 344-345) ${ }^{6}$.

Estes questionamentos apontam características importantes da personalidade científica e religiosa de Newton e que em muito se aproximam das doutrinas advindas do ethos puritano.

Newton sempre fora temente a Deus, no entanto, como os demais cientistas protestantes, buscava entender os elementos da obra divina e não o verdadeiro desígnio divino, o homem, nesse sentido, devido a sua limitação não seria capaz de fazê-lo, este não era um questionamento para Newton. Deus é quem em sua magnitude entenderia as coisas em si, em sua plenitude, o homem apesar de ser criado a sua imagem e semelhança, só conseguiria perceber aquilo que se apresenta de forma imediata no mundo, não a coisa em si, em sua essência.

É nesse sentido que Newton passa a valorizar o experimentalismo, observando o visível, a causa eficiente, mas tentando apreende-la via matemática, já que a razão, ou o ato de pensar seria a diferença entre o homem $^{7}$ e a natureza, afinal apenas o homem teria a capacidade de, ao compreender a dinâmica da natureza, valorizar e glorificar a obra divina.

Grosso modo, o pensamento teológico dos cientistas da época seguiam duas linhas de entendimento, segundo Loures (2010), Deus seria o elemento que fundamentaria a grandiosidade do comportamento da natureza, diferenciando-se apenas em sua forma de participação.

\footnotetext{
${ }^{6}$ Escrito em inglês arcaico. Transcrito como no original.

${ }^{7}$ Rene Descartes (1596-1650) em sua obra Discurso sobre o Método afirma que as criaturas não humanas seriam autômatos mecânicos, sendo apenas o homem capaz de raciocinar. Os escritos de Descartes foram fundamentais para construção do pensamento de Newton.
} 
[...] alguns entendiam que ele atuava constantemente (More, Boyle, Newton), enquanto outros como Descartes e Hobbes, entendiam que sua participação teria sido apenas a de garantir o primeiro motor (Barbinatti, 1999, p. 156), imprimindo a quantidade de movimento inicial ao mundo. (LOURES, 2010, p.17).

Esta perspectiva de Newton a respeito de Deus torna-se fundamental para compreensão de sua concepção de espaço.

Newton em sua formação analisou os debates travados entre Henry More e René Descartes. More entendia que a extensão seria um elemento divino, resultado da união entre o espaço, configurado como pura extensão imaterial, preexistente a matéria, e o "espírito da natureza", entendido por More como o poder de Deus sobre a matéria.

More dessa forma desarticula a existência de espaço da existência da matéria, no entanto é sobre este espaço que ocorre a potencialidade da matéria, como destaca Loures (2010).

O espaço adquire essa potencialidade de matéria, mas ela é desnecessária para tal. Esse espaço tem sua existência garantida, não pela presença de matéria, mas pela manifestação da ação divina (espírito da natureza) (LOURES, 2010, p.18).

O espaço “divinizado" de More seria pré-existente e independente da matéria e sobre ele atuariam as leis universais que foram criadas por Deus, ou em outras palavras, "o espaço seria a "morada" do espírito da natureza" (LOURES, 2010, p.18).

$\mathrm{O}$ que More pretendia era manter o aspecto onipresente, onisciente e onipotente da ação de Deus, rebatendo a ateização da natureza promovida por Descartes (Deus entendido apenas como motor inicial).

No entanto é importante destacar que o embate a "ateização" da natureza não se refere a questão levantada anteriormente sobre o domínio da natureza, pois este continuaria a existir, a divisão hierárquica entre homem e natureza continuaria a existir, a questão que More coloca é que Deus continuaria atuante, portanto imanente, através de sua concepção de espaço como morada do "espírito da natureza", este é o ponto fundamental de crítica em relação a Descartes.

Newton não considerava as colocações de More sobre o espaço como místicas, já que elas poderiam ser balizadas pela matemática (principalmente pela geometria). Nesse sentido, o conceito de espaço como algo absoluto (como definiria Newton), serviria como ferramenta 
conceitual para elaboração de suas teorias científicas, ampliando por consequência a glorificação da obra divina.

Em síntese, o espaço absoluto seria divino e imutável, sobre ele atuariam as leis universais, regidas pelo "espírito da natureza" e que poderiam ser compreendidas pela matemática, leis estas que modificam a matéria, que por sua vez poderiam ser analisadas através experimentos controlados. Assim temos no espaço absoluto uma concepção fundamentada tanto em termos teológicos como empíricos.

Com base nesta concepção, Newton publica em 1687 uma de suas principais obras: o Philosophiae Naturalis Principia Mathematica, apresentando através do conceito de espaço absoluto como se dá a dinâmica de movimento dos corpos celestes.

O espaço absoluto de Newton, considerado como uma entidade imutável, atuaria como um "pano de fundo fixo" para o movimento dos corpos celestes, este movimento absoluto seria o movimento verdadeiro, (a Terra estaria em movimento relativo em relação a outro referencial de observação, como a Lua, por exemplo, no entanto estaria em movimento absoluto em relação ao espaço absoluto). O movimento absoluto se dá em relação ao espaço absoluto, definindo o lugar absoluto das coisas. Como exemplo podemos citar que a Terra em seu plano de translação ao redor do Sol (O Principia também apresenta a lei da gravitação universal), teria seu lugar no espaço absoluto em determinado momento.

Justamente a característica transitória do lugar absoluto em relação ao momento, ou seja, a mudança constante de lugar que caracteriza a translação da Terra ao redor do Sol, definiria por sua vez algumas das leis universais que regem o "sistema mundo", fato que permitiria a análise das causas e efeitos derivados desse movimento nos elementos da natureza (matéria), portanto não é o espaço absoluto quem determina as transformações da matéria (pois este atua apenas como receptáculo) e sim as leis universais que atuam neste espaço.

As descobertas revolucionárias de Newton causaram um imenso fervor entre os cientistas naturais da época, tornando-o um dos mais importantes nomes do século XVIII.

Torna-se importante destacar também o papel da obra Geografia Geral de 1650 (não acabada) do alemão Bernhadus Varenius (1621/1622-1650) na concepção das teorias de Newton.

Varenius, foi sem dúvida o primeiro autor da Geografia a absorver no âmbito teóricometodológico as inovações da Ciência Moderna, fato associado ao período em que viveu, como destaca Bauab (2011). 
O cenário histórico existente à época de Varenius teve por característica [...], a eclosão de uma série de eventos que podem ser considerados extremamente importantes para a irrupção da modernidade: a eclosão da Reforma Protestante e a cisão inédita inserida por ela na Cristandade; o surgimento e a consolidação dos Estados Nacionais; a gênese da Ciência Moderna com a contribuição de autores de autores como Johannes Kepler e Galileu Galilei; a aproximação da filosofia com as problemáticas ensejadas pela ciência nascente através das obras de F. Bacon e Descartes; o mercantilismo estimulado, em parte, pelas conquistas ultramar dos chamados Descobrimentos Marítimos (BAUAB, 2011, p. 195).

Em sua obra Varenius dividia a Geografia em duas partes, a Geografia Geral que considerava a Terra enquanto conjunto e buscava compreender suas propriedades, no entanto sem se ater as particularidade das regiões, e a Geografia Especial que buscava compreender justamente a constituição das regiões, sendo estas subdivididas entre estudos corográficos e estudos topográficos (Bauab, 2011).

A Geografia Geral foi dividida em três livros: a Parte Absoluta, a Parte Relativa e a Parte Comparativa. Na Parte Absoluta, nos capítulos iniciais, Varenius apresenta as principais "descobertas" de seu tempo no que se refere a Terra entendida em seus aspectos mais fundamentais; seu movimento celeste, sua forma e seu tamanho, em seguida ele altera a escala de apresentação para os elementos do sistema Terra, dentre eles: as montanhas, os rios, as jazidas, as florestas e os desertos, os oceanos e os ventos. Na Parte Relativa, Varenius enfatiza a influência da luz solar diária sobre as diferentes partes do globo, principalmente no que se refere as diferenças climáticas. A Parte Comparativa, apresenta as características e formas de medição de distâncias entre lugares e a partir de lugares distintos, esta Parte ainda apresenta seis capítulos voltados a arte da navegação.

A ênfase de Varenius aos oceanos e aos barcos em sua obra se dão justamente pelo fato do escritor ter se mudado ainda jovem para Amsterdã, uma das principais áreas portuárias da Europa daquele período.

Newton mesmo se deparando com vários elementos da física cartesiana, que já haviam sido superados por ele, organizou duas edições da Geografia Geral de Varenius, uma em 1672 e outra em 1681. No entanto em ambas as edições foram acrescentadas questões de debate envolvendo o cartesianismo presente na obra e os conteúdos advindos das descobertas de Newton, como destaca Bauab (2011).

[...] podemos ressaltar amparados em Warntz (1989), que Newton e os newtonianos trataram, desde a edição de 1672 , de, sem macular esquemas e conteúdos eminentemente cartesianos, acrescentar ideias vinculadas às descobertas físicas que realizavam. Warntz (1989) ressalta que os esquemas 
e tabelas acrescentados por Newton, desde a edição de 1672, incluem aspectos referentes a matemática pura (Geometria aplicada à Geografia) e à matemática mista, abrangendo estudos de temas como refração da luz, altitudes, tempo, navegação, cartografia, projeções, entre outros (BAUAB, 2011, p. 216).

Torna-se claro o profundo interesse de Newton pela obra de Varenius, assim como sua tentativa de proporcionar um fecundo debate através de novas proposições, principalmente no que se refere ao conteúdo da Geografia Geral referente a Matemática Mista, entendida por Varenius como a matemática que "explicaria as propriedades da Terra e de suas partes relativas à quantidade, isto é, figura, situação, dimensões, movimentos, fenômenos celestes e outras propriedades similares (BAUAB, 2011, p. 214). O interesse de Newton também se dá pelo fato da obra de Varenius apresentar uma Geografia de caráter utilitarista, elaborada frente a crescente demanda por exatidão no que se refere ao nosso planeta, alinhando portanto o conhecimento científico aos desígnios da doutrina protestante (calvinista) do período.

As principais obras de Newton foram publicadas e divulgadas pela Royal Society, sendo que após a publicação de Optiks, Newton fora eleito presidente da instituição, o que ampliaria significativamente seu prestígio mundial. Suas obras, por possuírem um caráter universal, influenciaram os mais diversos ramos do conhecimento científico, dentre eles a Geografia.

Sabe-se que para a compreensão das bases que fundamentam a Geografia como ciência no século XIX com Humboldt e Ritter, seriam necessárias outras reflexões, sobre outros pensadores, principalmente germânicos, como Leibniz, Kant, Herder e Goethe. No entanto considerar-se-á neste artigo apenas o constructo por detrás da concepção de Geografia na Inglaterra, justamente pela influência direta da mecânica newtoniana e por esta ser concebida em um país de maioria protestante.

\section{A GEOGRAFIA IMPERIAL INGLESA}

A publicação e divulgação das obras de Newton pela Royal Society ampliaram significativamente seu prestígio como instituição promotora de inovações científicas, possibilitando que ao longo dos séculos XVIII, XIX e XX diversos outros países criassem suas academias ou sociedades científicas, como é o caso dos Estados Unidos, Austrália, China, Japão, Alemanha, Portugal, Itália, México, entre outros. No entanto, o caminho tomado pela Ciência, a partir do método cartesiano de divisão do conhecimento em parcelas, acabou conduzindo a criação de inúmeras sociedades científicas especializadas, principalmente no século XIX. Somente no Reino Unido, foram criadas mais de cinquenta 
sociedades científicas ao longo dos séculos que precederam a fundação da Royal Society, dentre elas a Royal Academy of Arts criada em 1768, a Royal Astronomical Society criada em 1820, a Royal Geological Society of Cornwall criada em 1814, a Royal Medical Society criada em 1773, entre outras. Deste grupo de instituições especializadas consideraremos para análise apenas a Royal Geographical Society of London, criada em 1830.

A Royal Geographical Society (RGS) foi criada inicialmente para promover campanhas exploratórias, tendo como intuito principal a descoberta e coleta de dados e informações cartografáveis dos mais variados pontos do globo:

As propostas iniciais da sociedade revelavam intenções de fundar um centro de coleta, acumulação e divulgação de conhecimento geográfico, gerando uma produção "cientifica" útil para a nação britânica, ao mesmo tempo que deveria se encarregar de assegurar a divulgação deste conhecimento para um público cada vez mais amplo (GEBARA, 2007, p. 106)

Gebara (2007) neste contexto ainda destaca que:

[...] a principal ênfase e os principais financiamentos conseguidos pela RGS nos primeiros anos, foram conferidos, não por acaso, a viagens e mapeamentos marítimos. Boa parte dos sócios e, principalmente, dos membros do conselho eram também da marinha britânica (GEBARA, 2007, p.105).

Cientistas e exploradores vinculados a RGS estabeleciam um constante intercâmbio de informações.

A articulação entre cientistas e exploradores compõe a espinha dorsal dos trabalhos: os exploradores levantando informações e esboçando seu mapeamento, a que os cientistas (as sociedades geográficas, sobretudo), incumbir-se-ão de sistematizar, catalogar, inferir e dar o tratamento científico e cartográfico final, produzindo material de apoio para novas e mais profundas incursões exploratórias (MOREIRA, 1987, p. 9)

Outro ponto importante para fundação da RGS em 1830 se associa ao auge do imperialismo inglês no século XIX, principalmente no que se refere a África e a Índia.

Torna-se importante destacar que uma das justificativas para o avanço imperialista sobre a África se associa a uma derivação da já citada segregação entre o homem racional e a natureza irracional. Segundo Thomas (1988):

[...] igual atitude de exclusão do outro se notava em escala ainda maior, face aos povos "primitivos" que não dispunham de atributos como os que também faltavam aos animais: tecnologia, linguagem inteligível, religião cristã (THOMAS, 1988, p.49). 
Em uma longa análise sobre os discursos africanistas vinculados aos exploradores da RGS, Gebara (2007) aponta uma série de situações em que as informações nativas eram desacreditadas ou representadas de forma confusa, conferindo portanto credibilidade apenas ao conhecimento adquirido pelo próprio explorador europeu.

O processo retórico através do qual os viajantes europeus desqualificavam ou desacreditavam as informações e o conhecimento geográfico dos africanos cumpria a função de constituir a voz da Europa como o único canal de expressão legitimamente científico (GEBARA, 2007, p.110).

Sendo assim, os dados coletados pela RGS serviriam também como base científica para o avanço justificado da Inglaterra imperialista sobre as áreas "primitivas" a serem conquistadas e sobre as áreas "primitivas" já conquistadas. A Geografia e mais especificamente a RGS, consolidavam-se nesse período como o mais importante braço científico da expansão imperial inglesa (Gebara, 2007).

Assim, a RGS teve como principal missão mapear os recursos e limites naturais destas áreas, ou seja, a perspectiva científica era de fato utilitarista. Neste bojo, o conceito de espaço absoluto de Newton, adaptado em nível de análise escalar para os elementos terrestres, ou seja, a analise de medidas móveis do espaço absoluto e que era possivel de ser verificada a partir da análise de outros corpos ${ }^{8}$, tornar-se-ia fundamental para as pretensões utilitaristas da Geografia inglesa imperialista.

As representações da Terra e seus elementos através da criação de cartas topográficas descreviam um espaço que não apresentava relação direta com a matéria presente neste espaço, ter-se ia, portanto, um espaço isotrópico, considerado apenas como receptáculo da matéria existente.

Na verdade, Newton, no que se refere a localização precisa dos elementos, utiliza como base a noção de espaço geométrico de Descartes, em que todos os elementos do mundo circundante teriam uma extensão (altura, comprimento e largura). A res extensa de Descartes poderia ser definida matematicamente e identificada em termos de localização precisa dentro do espaço absoluto.

Newton aprofunda o conceito de espaço de Descartes mais em um sentido de ampliar o conhecimento sobre o movimento dos corpos, do que no sentido de definir novas formas de compreender as multicausalidades que conduziram a localização dos elementos no espaço, ou seja tanto o espaço de Descartes como o de Newton são geométricos.

\footnotetext{
${ }^{8}$ A está transição de percepção Newton dá o nome de espaço relativo, no entanto este é dependente do espaço absoluto.
} 
Sob este contexto, a noção de espaço absoluto de Newton permitiu conceitualmente que a Geografia inglesa se debruçasse ainda mais sobre o método euclidiano/cartesiano, no que se refere a medição do espaço, pré-existentes a matéria, fato que permite apontar, em uma perspectiva reflexiva generalista e claro não esgotada, que a Geografia inglesa desse período não se dedicava a compreensão do espaço geográfico e sim do espaço cartográfico e topográfico de cunho geométrico, voltado apenas para descrição dos elementos em relação a sua localização, a leitura relacional estariam em um segundo plano.

Sobre isso Fonseca e Oliva (2001) destacam que:

Em termos de cartografia, considerada a ideia de espaço absoluto, ela pode ir pouco além de uma representação descritiva do espaço geográfico, atuando com o mais absoluto rigor com as métricas euclidianas. Disso resulta uma Cartografia de localização rigorosa dos objetos geográficos que, quando correlaciona objetos, o faz nos limites da distância euclidiana. Por isso, essa cartografia é forte no registro e na descrição rigorosa das distâncias euclidianas (FONSECA \& OLIVA, 2001, p.74).

A Geografia inglesa do período imperialista, via espaço absoluto, apresentava portanto um forte laço utilitarista com a Geografia entendida enquanto Matemática Mista, como afirmava Varenius em sua Geografia Geral, principalmente no que se refere a precisão localizacional dos elementos, como destaca Bauab (2005):

A geografia na ótica do autor, seria um ramo da matemática mista, ordenando na superfície geral, toda do planeta - dai o título de Geografia Geral - seus elementos constituintes. Daí a classificação precisa do que seria um monte, uma jazida, uma laguna, um lago, um pântano, ventos, rios, montanhas... Estaria, segundo o próprio Varenius, a matemática colocada enquanto a priori básico de todas as ciências, do entendimento dos fenômenos, ordenando-os, no caso da Geografia, espacialmente, isto em termos de uma localização precisa, inconteste (BAUAB, 2005, p.302-303).

Assim, a Geografia inglesa dos séculos XVIII e XIX de cunho cartográfico, portanto técnico e utilitarista, não visava estabelecer um constructo epistemológico voltado a emancipação da Geografia enquanto ciência, pois estava condicionada exclusivamente as necessidades de informação e de dados sobre as colônias inglesas.

Em síntese, o mapa entendido atualmente pelos geógrafos como ferramenta para análise do espaço geográfico, fora considerado durante o imperialismo inglês como o próprio objeto de estudo da Geografia. Fato que se dá frente ao prestígio alcançado pelo conceito de espaço absoluto de Newton, garantindo inclusive sua legitimidade enquanto área do conhecimento e seu lugar de apoio entre as ciências naturais. 


\section{CONSIDERAÇÕES FINAIS}

Buscou-se com este artigo estabelecer uma reflexão mais aprofundada sobre a origem da relação geométrica entre a Cartografia e a Geografia e que ainda povoa grande parte das mentes dos geógrafos da atualidade, principalmente no que ser refere a noção de espaço.

Esta reflexão, que a grosso modo é apresentada apenas como uma herança do posicionamento teórico-metodológico advindo da ciência cartesiana/newtoniana, pautada em uma noção de espaço absoluto, geométrico, não relacional, possui uma origem muito mais profunda e que em nossa construção se associa a Reforma Protestante, principalmente na Inglaterra dos séculos XVII, XVIII e XIX.

A conduta ética protestante que sustentou tanto os discursos como as atitudes dos cientistas ingleses da época deixou marcas profundas nas formas de entendimento sobre o espaço e sobre a natureza, inclusive definindo no senso comum a "verdadeira" ciência.

Dessa forma, o esforço reflexivo realizado neste artigo buscou apontar outros caminhos para a discussão da relação Cartografia/Geografia.

Torna-se importante destacar que a reflexão aqui realizada não considerou outros elementos de análise, como por exemplo aqueles derivados da Revolução Industrial, portanto necessitará de aprimoramento. Sabe-se também que a perspectiva de espaço apresentada neste artigo não reflete a perspectiva de espaço geográfico concebida na atualidade (apesar de grande parte dos geógrafos/cartógrafos ainda obedecerem os cânones do espaço absoluto), no entanto, se hoje o espaço geográfico é entendido em uma perspectiva relacional, isto se dá devido a crítica aguçada realizada por Leibniz à noção de espaço absoluto.

Dessa forma, ressaltamos a necessidade de ampliar a reflexão e compreensão da origem dos fatos, sua história, seu contexto, para que assim possamos avançar no debate epistemológico da Geografia, pois o que entendemos hoje nada mais é que reflexo de um passado de conflitos epistemológicos e que podem fornecer pistas sobre os caminhos a serem percorridos.

Qual Geografia queremos? Não há como obter a resposta sem entender a origem o contexto histórico, filosófico, político, econômico, social e cultural da pergunta.

Qual a função do conhecimento geográfico na Inglaterra do século XIX? Esta função ainda se mantém? A fundamentação teórico-metodológica se mantém? Existem novos elementos em discussão? Quais? Como abordá-los? O que queremos enquanto indivíduos e enquanto sociedade? Este exemplo de encadeamento lógico aponta apenas um dos caminhos para realização de um debate epistemológico na Geografia, no entanto esta construção exige 
obrigatoriamente o estabelecimento de um diálogo entre as áreas do saber geográfico, reinserindo ao debate uma perspectiva integradora capaz de dar respostas tanto para suas questões internas como para as problemáticas contemporâneas provenientes da relação homem/homem/natureza (homem entendido como individuo e/ou sociedade).

\section{REFERÊNCIAS BIBLIOGRÁFICAS}

ANSTEY, P. R. The philosophy of Robert Boyle. London: Routledge, 2003.

BAUAB, F. P. Da Geografia Medieval às origens da Geografia Moderna: contrastes entre diferentes noções de Natureza, Espaço e Tempo. Presidente Prudente: Tese (Doutorado em Geografia). Faculdade de Ciência e Tecnologia, Universidade Estadual Paulista "Julio de Mesquita Filho" - UNESP, 2005.

BAUAB, F. P. A Geografia Geral (1650) de Bernhardus Varenius: a modernidade da obra. Curitiba: RA'E GA, v. 23, 2011.

BÍBLIA, Português. A Bíblia Sagrada: Antigo e Novo Testamento. Trad. João Ferreira de Almeida. Brasília: Sociedade Bíblia do Brasil, 1995.

BURNET, G. Lives; characters and a sermon preached at the funeral of the honorable Robert Boyle. Dublin: A. Watson, 1824.

FONSECA, F. P. OLIVA, J. T. A Geografia e suas linguagens, o caso da cartografia. In. CARLOS, A. F. A. (Org.). A Geografia na Sala de Aula. 3 ed. São Paulo: Contexto, 2001

GEBARA, A. L. A. A África no discurso de Richard Francis Burton: uma analise da construção de suas representações. São Paulo: Tese (Doutorado em História). Faculdade de Filosofia, Letras e Ciências Humanas, Universidade de São Paulo - USP, 2007.

JONES, S. E. A brief survey of Sir Isaac Newton's Views on Religion. In. RHODES, M. D. \& MOODY, W. Converging Paths to Truth. Salt Lake City: Deseret Book, 2011.

LIVINGSTONE, D. N. Putting Science in its Place: geographies of scientific knowledge. Chicago: The University of Chicago Press, 2003.

LOURES, M. V. R. As bases teológico-experimentais do espaço absoluto de Newton. Florianópolis: PERI - Revista de Filosofia, UFSC. v.02, n. 02. 2010.

MERTON, R. K. Ensaios de sociologia da ciência. São Paulo: Editora 34, 2013.

MOREIRA, R. O que é Geografia. São Paulo: Editora brasiliense, 1987.

NEWTON, I. Opticks: or, a treatise of the reflections, refractions, inflections and colours of light. London: Printed for William Innys as the West-End of St. Paul's, 1730.

PESSOA JUNIOR, O. O dogmatismo cientifico de tradição materialista. In: SILVA, C. C. (Org.) Estudos de História e Filosofia das ciências: subsídios para aplicação no ensino. São Paulo: Livraria da Física, 2006.

THE ROYAL SOCIETY. List of fellows of the Royal Society, 1660 - 2007. London: Royal Society, 2007.

RYKEN, L. Santos no Mundo - os puritanos como realmente eram. São José dos Campos: Editora Fiel, 1992.

THOMAS, K. O homem e o mundo natural: mudanças de atitude em relação às plantas e aos animais (1500-1800). São Paulo: Companhia das Letras, 1988.

WEBER, M. A ética protestante e o espírito do capitalismo. São Paulo: Martin Claret, 2013.

ZATERKA, L. A filosofia experimental na Inglaterra do século XVII: Francis Bacon e Robert Boyle. São Paulo: Humanitas, 2004. 
Recebido em 18 de dezembro de 2016.

Aceito em 21 de novembro de 2017. 